\title{
Variation of Fatty Acids and Vitamin E Composition in Seed Oils of Some Plant Species
}

\author{
N. Habila ${ }^{1}$, H. M. Inuwa ${ }^{1}$, I. A. Aimola ${ }^{1}$, A. S. Agbaji ${ }^{2}$, Z. Ladan ${ }^{2}$, R. Shangodare ${ }^{2}$, \\ I. S. Williams ${ }^{3}$, O. B. Odjobo ${ }^{2} \&$ E. Ogabiela ${ }^{4}$ \\ ${ }^{1}$ Biochemistry Department, Ahmadu Bello University, Zaria, Nigeria \\ ${ }^{2}$ Research Department, National Research for Chemical Technology, Zaria, Nigeria \\ ${ }^{3}$ Science and Technology Department, Institute of Policy and strategic studies, Kuru, Nigeria \\ ${ }^{4}$ School of Applied sciences and engineering, Monash University, Gippsland campus, Victoria, Australia \\ Correspondence: N. Habila, Biochemistry Department, Ahmadu Bello University, Zaria, Nigeria. E-mail: \\ nathanhabila@yahoo.com
}

Received: April 13, 2012 Accepted: May 28, 2012 Online Published: August 10, 2012

doi:10.5539/jps.v1n2p55 URL: http://dx.doi.org/10.5539/jps.v1n2p55

\begin{abstract}
The composition of fatty acids (FA) and vitamin E in seed oils of Albezia lebbeck (AL), Citrus sinensis (CS), Terminalia catapa (TC), Tamarindus indica (TI) and Citrullus vulgaris (CV) was investigated. The oil yields were obtained by solvent extraction and analysed for fatty acids by Gas Chromatography Mass Spectroscopy (GC-MS). The oil yields of the seeds were found to be $8.22 \pm 0.55,20.00 \pm 1.50,35.60 \pm 1.60,24.00 \pm 1.20 \%$ and $9.42 \pm 1.30$ percent AL, CS, TC, CV, and TI respectively. Both saturated and unsaturated FA were identified in all the seed oils with the latter being the predominant with $77.70 \%$ in $\mathrm{CV}, 60.76 \%$ in $\mathrm{CS}, 56.98 \%$ in $\mathrm{AL}$, $54.58 \%$ in TC and $34.52 \%$ in TI. Vitamin E was highest in CV $27.51 \pm 2.42 \mathrm{mg} / \mathrm{ml}$ and lowest in TI $10.60 \pm 1.50$ $\mathrm{mg} / \mathrm{ml}$. There was significant decrease in percentage saturated FA, increase in percentage unsaturated FA with increase in vitamins E concentration in all the seed oils. The oils have many FA such as oleic acid, eicosadienoic acid and $\alpha$-linoleic acid which could be of biological and industrial significance to humans.
\end{abstract}

Keywords: seed oil, fatty acids, gas chromatography, Vitamin E, essential fatty acids

\section{Introduction}

Fatty acids are chains of covalently linked carbon atoms, bearing hydrogen atoms which terminate in a carboxyl group that is responsible for their properties as acids. The naturally occurring fatty acids in plants are for the most part unbranched molecules but complex structures with branched or cyclic chains do occasionally occur, particularly in lower biological forms, (Mc-Murray et al., 2010). Two general types of fatty acids exist, saturated and unsaturated, of which, more than 100 different fatty acids have been identified (Horton et al., 2006). In recent years, there has been observed, a trend in human diets towards reduction of saturated fats such as palmitic acid (C16:0) and an increase in polyunsaturated (C18:2 and C18:3), and monounsaturated (C18:1) fats (Mailer, 2004). Human body can produce all the fatty acids (FA), it needs, except linoleic acid (LA) and $\alpha$ - linoleic acid (ALA) which are widely distributed in plant oils/vegetable oils and are regarded as essential fatty acids (EFA) (Halver, 2011). Many vegetable oils are consumed directly or indirectly as ingredients in food and the oils serve a number of purposes in this role (Dubois et al., 2007). A high consumption of vegetable oils has been reported (Dobson et al., 1997; Ayerza \& Coastes, 2005; Dubois et al., 2007; Rezanka \& Singler, 2009; Ixtaina et al., 2011) which has greatly increased the demand for alternative plant based oils which are low in saturated fats, higher in mono-unsaturates and better sources of omega-3 fatty acid.

Oilseed crops are generally grown for the purpose of oil in their seeds and they vary considerably in their oil content, quality, and composition. These factors rely heavily on the crop species or cultivar and upon the environmental conditions in which the crop is grown (Mailer, 2004). A large quantity of oil and fats, whether for human consumption or for industrial purposes is presently derived from plant sources (Ramadan et al., 2006). To meet the increasing demands for oil, improvements are being made to produce unique and desirable oils, therefore increasing interest in newer sources of edible oils from natural sources. Plant seeds are important sources of oils of nutritional, industrial and pharmaceutical significance (Ramadan et al., 2006). No oil from any 
source has been found to be suitable for all purposes because oils from different sources generally differ in their composition. This necessitates the search for new sources of novel oils, of which several plants are now grown, not only for food and fodder, but also for a striking variety of products with applications in industry, including essential oils and pharmaceuticals.

Vegetable oils not only provide high quality food, containing essential nutrients for life, but also bestow bioactive compounds that have particular clinical significance (Mehmood et al., 2008). The advent of alternative vegetable oil production has also triggered the insatiable search for alternative sources of raw material for this purpose. More so, there could be a variable chemical composition depending on several factors such as the cultivation environment (Ixtaina et al., 2011). In addition, there is an increase in technological developments, particularly with the genetic modification of oilseeds to create a new range of products. For cooking oils and salad dressings, plant breeders have selected cultivars with lower levels of polyunsaturated and monounsaturated fats and an increase in monounsaturates for increased oxidative stability. New developments include oils with increased stearic acid to provide margarine type fats without the need for hydrogenation and the subsequent production of trans-fatty acids (Mailer, 2004). It is in the light of this scenario that we report here the FA and vitamin E composition of the seed oils of Albezia lebbeck, Citrus sinensis, Tamarindus indica, Terminalia catapa and Citrullus vulgaris by solvent extraction and Gas Chromatography Mass Spectroscopy (GCMS) with a view to explore the possibility of potential sources of oils for the future.

\section{Materials and Methods}

\subsection{Seed Collection}

The fruits of Albezia lebbeck (AL), Citrus sinensis (CS), Terminalia catapa (TC), Tamarindus indica (TI) and Citrullus vulgaris (CV) were collected in Zaria, Nigeria in April 2011 and identified in the Herbarium of Department of Biological Sciences, Ahmadu Bello University Zaria, Nigeria. They were manually cleaned and the seed kernels of each fruit were removed by excising the pericarps.

\subsection{Oil Extraction}

The seed kernels $(40 \mathrm{~g})$ were blended using a blender. The blend was extracted with petroleum ether $\left(40^{\circ} \mathrm{C}-60^{\circ} \mathrm{C}\right)$ in a Soxhlet apparatus by thermal cycles at $80^{\circ} \mathrm{C}$ for $8 \mathrm{~h}$, following the IUPAC standard method (IUPAC, 1992). The solvent was removed using a rotator vacuum evaporator at $40^{\circ} \mathrm{C}$. The oil content was gravimetrically determined and expressed as weight percent on dry basis (Ixtaina et al., 2011).

\subsection{Analysis}

\subsubsection{GCMS Analysis}

The fatty acid composition was determined as methyl esters. Briefly, $100 \mu \mathrm{l}$ oil plus $1 \mathrm{ml} 10 \%$ potassium hydroxide in methanol were heated for 45 minutes at $85^{\circ} \mathrm{C}$. Fatty acids were methylated with $1 \mathrm{ml}$ boron triflouride-methanol-complex (20\% solution in methanol) plus $1 \mathrm{ml}$ methanol for 45 minutes at $60^{\circ} \mathrm{C}$ and then extracted from the methanolic phase with petroleum ether. The analyte, $1 \mu 1$ was injected in the column equipped with column oven temperature of $60^{\circ} \mathrm{C}$ and column flow of $0.99 \mathrm{ml} / \mathrm{min}$. The compounds were identified by the GCMS intensity of retention time (RT) and by comparison with those present in the National Institute for Standard Technology Computer DataBank library of 2010. The results were expressed as the relative percentage of each individual fatty acid (FA) present in each sample given by the corresponding RT.

\subsubsection{Vitamin E}

The vitamin E level was estimated using the spectrophotometric method of Tutem et al. (1997). The concentration of vitamin $\mathrm{E}$ in all the seed oils was obtained using a standard curve plot.

\section{Results}

The oil yields of the 5 seed oils are presented in Table 1. The yield showed that TC had the highest oil content of $35.60 \pm 1.60$ percent. It was followed by CV $(24.00 \pm 1.20 \%)$, CS $(20.00 \pm 1.50 \%)$, TI $(9.42 \pm 1.30 \%)$ and AL $(8.22 \pm 0.55 \%)$. The Vitamin E (VE) concentration was found to be $27.51 \pm 2.42 \mathrm{mg} / \mathrm{ml}$ in CV, $25.40 \pm 2.10$ $\mathrm{mg} / \mathrm{ml}$ in CS, $19.00 \pm 1.33 \mathrm{mg} / \mathrm{ml}$ in AL, $15.60 \pm 2.30 \mathrm{mg} / \mathrm{ml}$ in TC and $10.60 \pm 1.50 \mathrm{mg} / \mathrm{ml}$ in TI (Table 1). The VE of CV is the highest with $27.51 \mathrm{mg} / \mathrm{ml}$ and $\mathrm{TI}$ is lowest with $10.60 \mathrm{mg} / \mathrm{ml}$ concentration. The oil content showed that the seeds have good yield which could be exploited. 
Table 1. Percentage oil yield and Vitamin E concentration of five plant seed oils

\begin{tabular}{llll}
\hline SR. NO. & SEED SAMPLE & OIL YIELD $(\%)$ & VITAMIN $(\mathrm{mg} / \mathrm{ml})$ \\
\hline 1 & Albezia lebbeck & $8.22 \pm 0.55$ & $19.00 \pm 1.33$ \\
2 & Citrus sinenssis & $20.00 \pm 1.50$ & $25.40 \pm 2.10$ \\
3 & Terminalia catapa & $35.60 \pm 1.60$ & $15.60 \pm 2.30$ \\
4 & Citrullus vulgaris & $24.00 \pm 1.20$ & $27.51 \pm 2.42$ \\
5 & Tamarindus indica & $9.42 \pm 1.30$ & $10.60 \pm 1.50$ \\
\hline
\end{tabular}

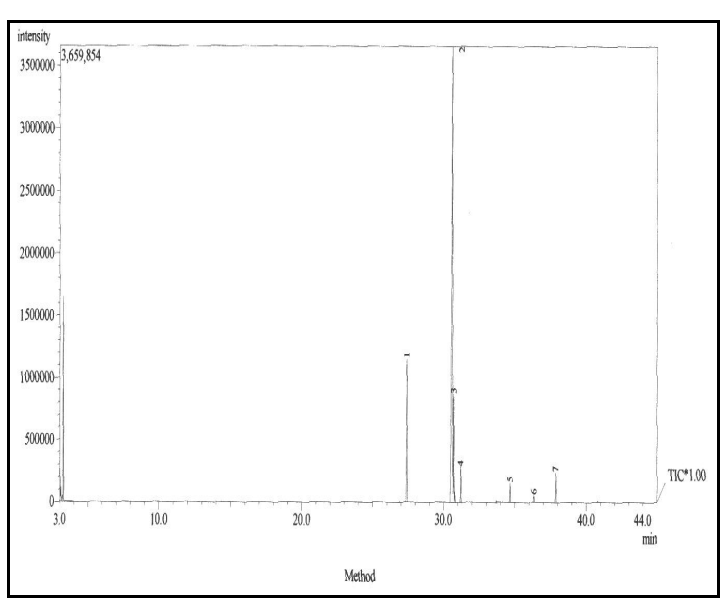

Figure 1. Fatty acid composition of Albezia lebbeck seed oil. Peak $1(\mathrm{RT}=27.42 \mathrm{~min})$ is pentadecanoic acid $(17.92 \%)$, peak $2(\mathrm{RT}=30.61 \mathrm{~min})$ is 11 ,

14-eicosadienoic acid $(56.98 \%)$, peak $3(\mathrm{RT}=30.71$

$\mathrm{min})$ is oleic acid $(13.54 \%)$, peak $4(\mathrm{RT}=31.21$ $\min )$ is heneicosanoic acid $(4.55 \%)$

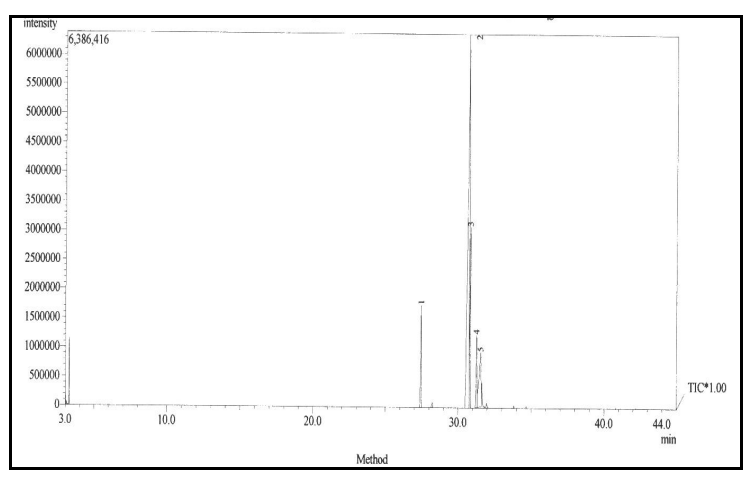

Figure 3. Fatty acid composition of Citrullus vulgaris seed oil. Peak $1(\mathrm{RT}=27.46)$ is pentadecanoic acid $(13.02 \%)$, peak $2(\mathrm{RT}=30.73$ $\mathrm{min})$ is 11,14 -eicosadenoic acid $(47.66 \%)$, peak 3 $(\mathrm{RT}=30.83 \mathrm{~min})$ is oleic acid $(23.09 \%)$, peak 4 (RT $=31.28 \mathrm{~min})$ is heneicosanoic acid $(9.29 \%)$, peak 5

$(\mathrm{RT}=31.56 \mathrm{~min})$ is $\alpha$-linoleic acid $(6.95 \%)$

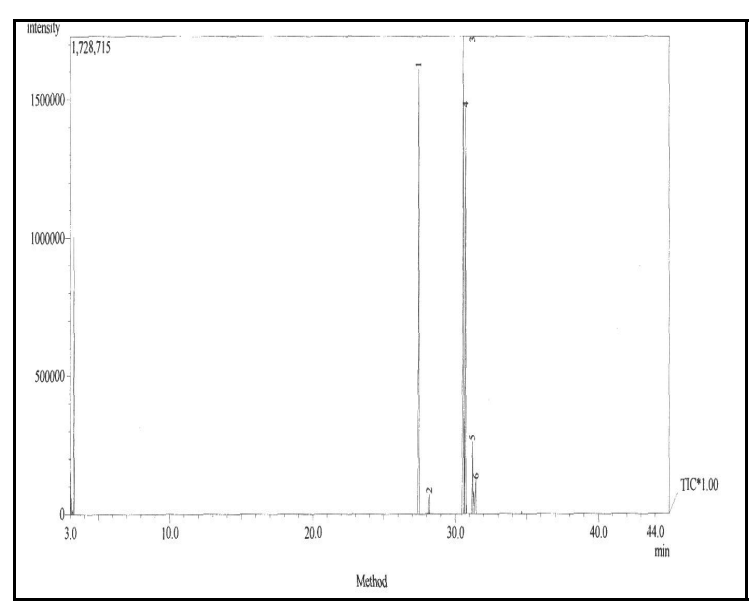

Figure 2. Fatty acid composition of Citrus sinensis seed oil. Peak $1(\mathrm{RT}=27.44 \mathrm{~min})$ is pentadecanoic acid $(30.65 \%)$, peak $2(\mathrm{RT}=28.17 \mathrm{~min})$ is amyl nitrite

$(1.31 \%)$, peak $3(\mathrm{RT}=30.57 \mathrm{~min})$ is linoleic acid $(32.86 \%)$, peak $4(\mathrm{RT}=30.73 \mathrm{~min})$ is oleic acid $(27.90 \%)$, peak $(\mathrm{RT}=31.21 \mathrm{~min})$ is palmitic acid $(4.95 \%)$

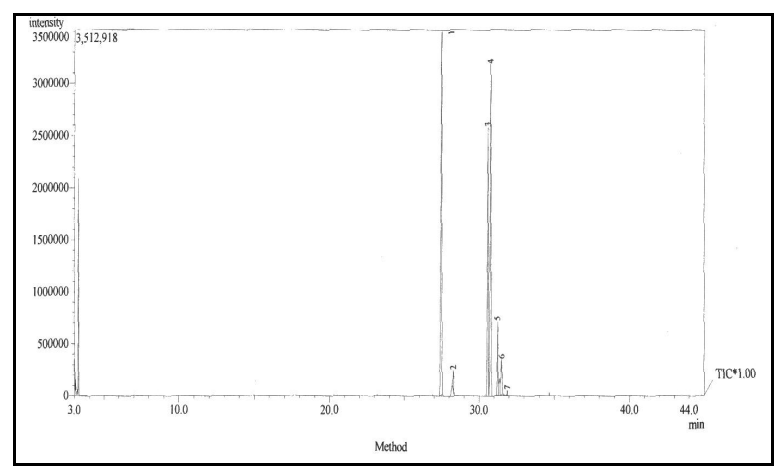

Figure 4. Fatty acid composition of Taminalia catapa seed oil. Peak $1(\mathrm{RT}=27.50 \mathrm{~min})$ is pentadecanoic acid $(33.17 \%)$, peak $2(\mathrm{RT}=28.28 \mathrm{~min})$ is octadecanoic acid $(1.87 \%)$, peak $3(\mathrm{RT}=50.60 \mathrm{~min})$ is linoleic acid $(24.44 \%)$, peak $4(\mathrm{RT}=30.78 \mathrm{~min})$ is oleic acid $(30.14 \%)$ and peak $5(\mathrm{RT}=31.24 \mathrm{~min})$ is heneicosanoic acid $(6.73 \%)$

The FA analyses of the five seed oils are presented in the chromatograms on Figures 1-4. The FA composition of AL (Figure 1) revealed the presence of unsaturated fatty acids (UFA) namely, oleic acid (13.54\%) (peak 3) and 11, 14-eicosadienoic acid (56.98\%) (peak 2). This is higher than the saturated FA (SFA) namely, pentadecanoic acid (17.92\%) (peak 1) and heneicosanoic acid (4.55\%) (peak 4). 
Figure 2 shows the chromatogram of FA in CS which contains linoleic acid (32.82\%) (peak 3), oleic acid is $27.90 \%$ (peak 4). There were only two SFA which were detected in CS seed oil namely, pentadecanoic acid (30.65\%) (peak 1) and palmitic acid (4.95\%) (peak 5).

In figure 3, the percentage composition of UFA in CV revealed that 11, 14-eicosadienoic acid (peak 2) is $47.66 \%$, oleic acid (peak 3) is $23.09 \%$, and $\alpha$-linoleic acid (peak 5) 6.95\%. This gives a total of $77.70 \%$ UFA in CV. The SFA present in CV are pentadecanoic acid (13.02\%) (peak1) and heneicosanoic acid (9.29\%) (peak 4).

The UFA composition is higher than SFA (Figure 4) in TC which revealed the presence of oleic acid (30.14\%) (peak 4) and linoleic acid (24.44\%) (peak 3). The SFA present are pentadecanoic (33.17\%) (peak 1) and heneicosanoic acid (6.73\%) (peak 5).

The fatty acid composition of TI is shown in Table 2. The most abundant UFA present is oleic acid which is $10.51 \%$. The total percentage of UFA and SFA in TI is $36.62 \%$ and $30.27 \%$ respectively. The variation in the composition and oil yield observed in this study could be related to several factors for example changes in temperature, extraction and environmental effect (Ennouri et al., 2005).

Table 2. Fatty acid composition of Tamarindus indica fruit seed oil

\begin{tabular}{llll}
\hline SR. NO. & FATTY ACID & COMPOSITION (\%) & RT (min) \\
\hline 1 & Oleic acid & 10.51 & 17.17 \\
2 & Linoleic acid & 7.78 & 17.52 \\
3 & 11-Eicosenoic acid & 6.10 & 18.78 \\
4 & $5,8,11,14-$-icosatetraenoic acid & 5.66 & 18.58 \\
5 & $\alpha$ Linoleic acid & 4.49 & 18.17 \\
6 & 11-Dodecenoic acid & 2.42 & 19.43 \\
7 & Palmitic acid & 8.22 & 15.41 \\
8 & Nonadecanoic acid & 5.50 & 19.86 \\
9 & Tetracosanoic acid & 5.59 & 22.22 \\
10 & Heneicosanoic acid & 2.08 & 23.14 \\
11 & Heptadecanoic acid & 1.94 & 16.28 \\
12 & Tricosanoic acid & 1.94 & 21.34 \\
13 & Stearic acid & 5.00 & 20.16 \\
\hline
\end{tabular}

\section{Discussion}

The composition of the fatty acids (FA) in the plant fruit seed oils studied showed presence of various components which may be of nutritive value since they contain appreciable quantity of essential FA (EFA) and vitamin E (VE) that play important role in human life. EFA like linoleic acid, oleic acid and eicosadienoic acid are necessary fats that humans cannot synthesize and, hence, must be obtained from diet (Mc-Murray et al., 2010). The EFA are long-chain polyunsaturated FA (PFA) derived from linolenic, linoleic and oleic acids (Rezanka \& Sigler, 2009). The omega-3 FA is derived from linolenic acid, omega-6 from linoleic acid and omega-9 from oleic acid (Schmitz \& Ecker, 2008). Dietary lipids serve not only as an energy source but also provide the EFA required for life (Danderjagt et al., 1996).

The results in this study revealed that, the most abundant UFA is 11,14 -eicosadienoic acid which is $56.98 \%$ in $\mathrm{AL}$ and the least abundant UFA was found in seeds of TI which contain $4.47 \% \alpha$-linoleic acid. In CV, the 3 UFA found are 11, 14-eicosadienoic acid (47.66 \%), oleic acid (23.09\%) and $\alpha$-linoleic acid (6.95\%) which gives a total of $77.70 \%$ UFA in CV. In the 5 seed oils, oleic acid was found in all the seed oils at different proportions, of which oleic acid in TC was the highest (30.14\%) and oleic acid in AL was the lowest (13.54 \%). Linoleic acid was found in all the seed oils except the seed oil of AL. In all the seed oils, only TI had five (5) different UFA namely oleic acid, linoleic acid, 11 -eicosenoic acid, 5, 8, 11, 14-eicosatetraenoic acid and $\alpha$-linoleic acid. On the contrary, the total UFA is $34.52 \%$ in TI which is the lowest compared to others. The values of some of the FA in TI were found to be different from that earlier reported by Ajayi et al. (2006). This could be due to the variation 
in environmental conditions in which the plants were grown. The levels of FA are known to vary largely with season and geographical location (Schreiber et al., 2006; Ogwok et al., 2008). The variation in the FA composition could be due to the fact that the plant seeds are from different ecological origin.

EFAs support the cardiovascular, reproductive, immune and nervous systems. The human body needs EFAs for the synthesis and repair of cell membranes, enabling the cells to obtain optimum nutrition and expel harmful waste products (Herbaut, 2006). A primary function of EFAs is the production of prostaglandins, which regulate body functions such as heart rate, blood pressure, blood clotting, fertility, conception, and play a role in immune function by regulating inflammation and encouraging the body to fight infection (Patil \& Gislerod, 2006; Horton et al., 2006). EFAs are also needed for proper growth in children, particularly for neural development and maturation of sensory systems (Ayerza \& Coastes, 2005). The seed oils samples can provide a good level of EFA which could participates in a variety of metabolic pathways when taken in diets and activated (Mullins et al., 1997), but excessive levels of certain FA (omega-6 FA) may increase the probability of a number of diseases (Hibbeln et al., 2006). Therefore, the ratio and the percentage of omega- 3 and omega- 6 needs to be satisfactory for human diet (Miniadis-Meimaroglou et al., 2007).

In all the seed oils, VE was found to be highest in CV $(27.51 \mathrm{mg} / \mathrm{ml})$ and lowest in TI $(10.60 \mathrm{mg} / \mathrm{ml})$ as shown in Table 1. There was significant decrease in SFA, increase in UFA with increase in VE concentration in all the seed oils. It indicates that there is a relationship between VE and FA composition of plant seed oils. VE is a fat soluble vitamin which is known to have several biological functions of which the most important is the antioxidant function (Bell, 1987). Plant seed oils with high concentration of VE and EFA are reported to be useful in metabolic and physiological activities in life (Chen, 2005). In another report, TC seed oil injection have been used in clinical trials for the treatment of rectal prolapse in children (Angerpointner, 2005) and it has also shown effects on plasma lipids and low density lipid oxidation in healthy men and women (Hyson, 2002).

This finding highlights the presence of EFA and VE in significant quantities in the 5 seed oils with significant yields in CV, TC and CS. Recently, FA of plant origin has been reported to play role as antimalarial, antimycobacterial and antifungi agents (Carballeira, 2008). The oils could be utilized as a useful source of vegetable oil bearing in mind that seed oil production is an important part of agricultural economy. Vegetable oil is known as an alternative fuel for diesel engines and for heating oil burners. Other methods of extraction like the sodium-phase extraction and methylation procedures to analyse free fatty acids in lipid-rich seeds have been developed to improve oil yield (Laffargue et al., 2007). We conclude therefore, that there is significant variation in FA, VE and oil yield. These variations observed in this study could be due to many factors like soil types and ecological origin of the plant species.

\section{Acknowledgement}

We appreciate National Research Institute for Chemical Technology Zaria-Nigeria for research facilities. We thank Mr. Nok E.J. for consistent laboratory assistance.

\section{References}

Angerpointner, T. A. (2005). The treatment of rectal prolapsed in children with phenol in Almond oil injection. Journal of Paediatrics Surgery, 40, 12-17.

Ajayi, I. A., Oderinde, R. A., Kajogbola, D. O., \& Uponi, J. I. (2006). Oil content and fatty acid composition of some underutilized legumes from Nigeria. Food Chemistry, 99, 115-120. http://dx.doi.org/10.1016/j.foodchem.2005.06.045

Ayerza, R., \& Coates, W. (2005). Ground chia seed and chia oil effects on plasma lipids and fatty acids in the rat. Nutrition Research, 25, 995-1003. http://dx.doi.org/10.1016/j.nutres.2005.09.013.

Bell, E. F. (1987). History of vitamin E in human nutrition. American Journal of Clinical Nutrition, 46, 7-30.

Carballeira, N. M. (2008). New advances in fatty acids as antimalarial, antimycobacterial and antifungal agents. Progress in Lipid Research, 47(1), 50-61. http://dx.doi.org/10.1016/j.plipres.2007.10.002

Chen, C. Y. (2005). Flavonoids from almond skins are bio-available and act synergistically with vitamins $\mathrm{C}$ and $\mathrm{E}$ to enhance hamster and human LDL resistance to oxidation. Journal of Nutrition, 135, 1366-1373.

Dobson, G., William, W. C., \& Sebedo, J. L. (1997). Saturated bicyclic fatty acids formed in heated sunflower oils. Chemistry and Physics of Lipids, 87(2), 137-147. http://dx.doi.org/10.1016/S0009-3084(97)00038-4

Dubois, V., Breton, S., Linder, M., Fanni, J., \& Parmentier, M. (2007). Fatty acids profile of 80 vegetable oils with regard to their nutritional potential. European Journal of Lipids Science and Technology, 109, 710-732. http://dx.doi.org/10.1002/ejlt.200700040 
Ennouri, M., Bourreat, E., Laurence, M., Hamadi, A. (2005). Fatty acid composition and rheological behaviour of pricky peer seed oil. Food Chemistry, 93(3), 431-437. http://dx.doi.org/10.1016/j.foodchem.2004.10.020

Halver, J. E. (2011). Lipids and fatty acids. FAO Corporate document repository. pp. 1-11.

Herbaut, C. (2006). "Omega -3 and health". Revue Medicale de Bruxelles, 27(4), 355-360.

Hibbeln, J. R., Nieminen, L. R. G., Blasbalg, T. L., Riggs, J. A., \& William, E. M. L. (2006). Healthy intake of n-3 and n-6 fatty acids: estimations considering worldwide diversity. The American Journal Clinical Nutrition, 83, 1483-1493.

Horton, R. H., Moran, L. A., Scrimgeour, K. G., Perry, M. D., \& Rawn, J. D. (2006). Principles of Biochemistry, (4th ed.). Pearson International Edition, pp. 254-255.

Hyson, D. A. (2002). Almonds and almond oil have similar effects on plasma lipids and LDL oxidation in healthy men and women. Journal of Nutrition, 132, 703-707.

IUPAC. (1992). Standard methods for analysis of oils, fats and derivates. (7th ed.). International Union of Pure and Appied Chemistry, Blackwell scientific publications Inc., Oxford England.

Ixtaina, V. Y., Martinez, M. L., Spotorno, V., Mateo, C. M., Maestri, D. M., Diehl, B. W. K., .. Tomas, M. C. (2011). Characterization of chia seed oils obtained by pressing and solvent extraction. Journal of Food Composition and Analysis, 24(2), 166-174. http://dx.doi.org/10.1016/j.jfca.2010.08.006.

Laffargue, A., Kochko, A., \& Dusserts, S. (2007). Development of sodium-phase extraction and methylation procedures to analyse free fatty acids in lipid-rich seeds. Plant Physiology Biochemistry, 45(3-4), 250-257. http://dx.doi.org/10.1016/j.plaphy.2007.01.012

Mailer, R. J. (2004). Oilseeds review. Encyclopedia of Grain Science. pp. 380-386.

Mc-Murry, J., Castellion, M., Ballantine, D. S., Hoeger, C. A., \& Peterson, V. E. (2010). Fundamentals of general, organic and biological chemistry. Pearson Education Inc. Upper Saddle River. pp. 758-762.

Mehmood, S., Orhan, I., Ahsan, Z., Aslan, S., \& Gulfraz, M. (2008). Fatty acids composition of seed oil of

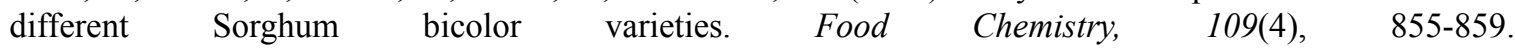
http://dx.doi.org/10.1016/j.foodchem/.2008.01.014

Miniadis-Meimaroglou, S., Dimizas, C., Loukas, V., Moukas, A., Vlachos, A., Thomaidis, N., Paraskevopoulou, V., \& Dasenakis, M. (2007). Proximate composition, fatty acid, cholesterol, minerals in frozen red progy. Chemistry and Physics of Lipids, 146(2), 104-110. http://dx.doi.org/10.1016/j.chemphyslip.2006.12.009

Mullins, D. W., Alleva, D. G., Burger, C., Elgert, K. D., \& Watkins, P. A. (1997). Fatty acid activation. Progress in Lipid Research, 36, 55-83. http://dx.doi.org/10.1016/S0163-7827(97)00004-0

Ogwok, P., Muyonga, J. H., \& Sserunjogi, M. L. (2008). Fatty acid profile and stability of oil from the belly flaps of Nile perch. Food Chemistry, 108(1), 103-109. http://dx.doi.org/10.1016/j.foodchem.2007.10.050

Patil, V., \& Gislerod, H. R. (2006). The importance of omega-3 fatty acids in diet. Current Science, 90, 908-909.

Ramadan, M. F., Sharanabasappa, G., Seetharam, Y. N., Seshagiri, M., \& Moersel, J. T. (2006). Characterization of fatty acids and bioactive compounds of Kachnar (Bauhinia purpurea L.) seed oil. Food Chemistry, 98(2), 359-365. http://dx.doi.org/10.1016/j. foodchem.2005.06.018

Rezanka, T., \& Sigler, K. (2009). Odd-numbered very long-chain fatty acid from the microbial, animal and plant kingdoms. Prog. Lipid Res, 48(3-4), 206-238. http://dx.doi.org/10.1016/jplipres.2009.03.003

Schreiber, A., Worheide, G., \& Thiel, V. (2005). The fatty acids of calcareous sponges. Chemistry and Physics of Lipids, 143(1-2), 29-37. http://dx.doi.org/10.1016/j.chemphyslip.2006.06.001

Schmitz, G., \& Ecker, J. (2008). The opposing effects of omega-3 and omega-6 fatty acids. Progress in Lipid Research, 47(2), 147-155. http://dx.doi.org/10.1016/jplipres.2009.03.003

Tutem, E., Apak, R., Esma, G., \& Kevser, S. (1997). Spectrophotometric determination of Vitamin E ( $\alpha$-tocopherol) using copper (II)-neocuproine reagent. Talanta, 44(2), 249-255.

Vanderjagt, J. D., Glew, R. H., Bizzozero, O. A., Saha, A. K., \& Omene, J. A. (1996). Altered fatty acid composition of serum phospholipids in protein-malnourished Nigerian children. Nutrition Research, 16(8), 1307-1312. http://dx.doi.org/10.1016/0271-5371(96)00139-X 